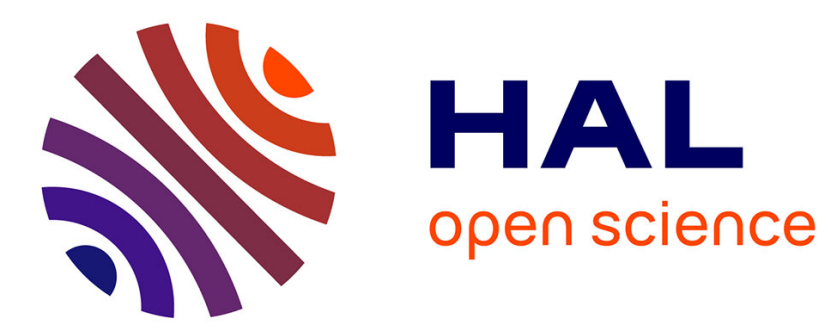

\title{
THERMOMECHANICAL MODELLING AND SIMULATION OF C38 THIXOEXTRUSION STEEL
}

Eric Becker, Laurent Langlois, Véronique Favier, Régis Bigot

\section{To cite this version:}

Eric Becker, Laurent Langlois, Véronique Favier, Régis Bigot. THERMOMECHANICAL MODELLING AND SIMULATION OF C38 THIXOEXTRUSION STEEL. Solid State Phenomena, 2014, 217-218, pp.130-137. 10.4028/www.scientific.net/SSP.217-218.130 . hal-01097241

\section{HAL Id: hal-01097241 \\ https://hal.science/hal-01097241}

Submitted on 19 Dec 2014

HAL is a multi-disciplinary open access archive for the deposit and dissemination of scientific research documents, whether they are published or not. The documents may come from teaching and research institutions in France or abroad, or from public or private research centers.
L'archive ouverte pluridisciplinaire HAL, est destinée au dépôt et à la diffusion de documents scientifiques de niveau recherche, publiés ou non, émanant des établissements d'enseignement et de recherche français ou étrangers, des laboratoires publics ou privés. 


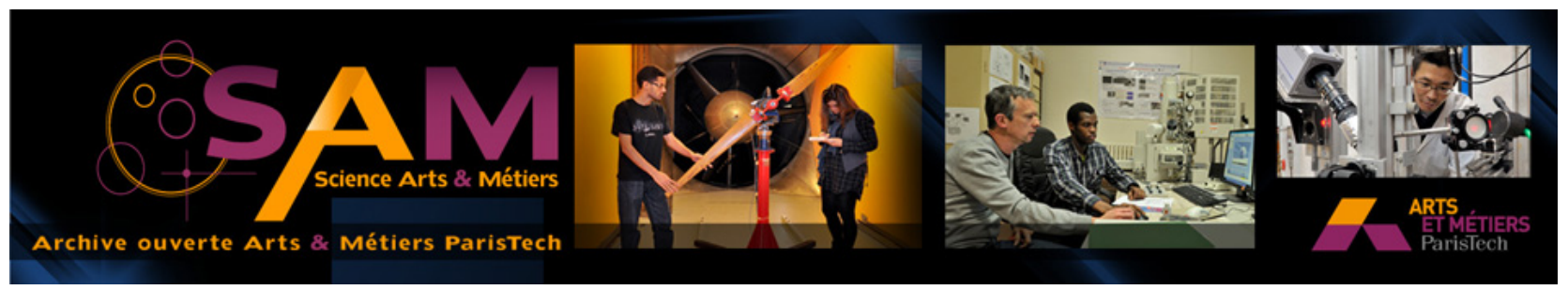

Science Arts \& Métiers (SAM)

is an open access repository that collects the work of Arts et Métiers ParisTech researchers and makes it freely available over the web where possible.

This is an author-deposited version published in: http://sam.ensam.eu

Handle ID: .http://hdl.handle.net/10985/9127

\section{To cite this version :}

Eric BECKER, Laurent LANGLOIS, Véronique FAVIER, Régis BIGOT - THERMOMECHANICAL MODELLING AND SIMULATION OF C38 THIXOEXTRUSION STEEL - Solid State Phenomena Vol. 217-218, p.130-137 - 2014 


\title{
THERMOMECHANICAL MODELLING AND SIMULATION OF C38 THIXOEXTRUSION STEEL
}

\author{
Eric BECKER ${ }^{1, a}$, Laurent LANGLOIS ${ }^{1, b}$, Véronique FAVIER $^{2, c}$ and \\ Régis BIGOT ${ }^{1, d}$
}

${ }^{1}$ Laboratoire de Conception, Fabrication et Commandes - Arts et Métiers ParisTech - 4, rue Fresnel, F-57070 METZ FRANCE

${ }^{2}$ Laboratoire Procédés et Ingénierie en Mécanique et Matériaux - Arts et Métiers ParisTech - 151, boulevard de l'Hôpital, F-75013 PARIS France

aeric.becker@ensam.eu, blaurent.langlois@ensam.eu, ㄷveronique.favier@ensam.eu, dregis.bigot@ensam.eu.

Keywords: thixoforging, micro-macro modelling, steel, tool/slug heat exchange, semi-solid.

\begin{abstract}
The present paper focuses the modelling and the simulation of a direct thixoextrusion test achieved on C38 semi-solid steel. To validate the modelling and the simulation, it is important to get various experimental informations during the test and to correlate them with simulated results. In a previous paper (Becker et al, 2008), the macro and micro structure obtained for different process parameters during thixoextrusion of C38 were investigated. In this work, those results are correlated to those obtained by simulations of the processing. The constitutive equation of the material is given by a multi-scale modelling based on micromechanics and homogenization techniques, labelled as micro-macro modelling (Favier et al, 2009). The parameters of the model are determined (i) using literature results and (ii) to match various experimental measurements obtained during the test and described in Becker et al (2008) such as the die temperature during the test and the load-displacement curve. Comparisons between experimental and simulated reveal the presence of complex temperature field and the presence of zones having very low viscosities. These zones contribute actively to the semi-solid material flow.
\end{abstract}

\section{INTRODUCTION}

The steel forming at the semi-solid state by thixoforging offers many advantages. This process can be carried out to manufacture near net-shape parts of complex shape with a reduced forging load, in one step and with improved mechanical properties compared with the casting process [1, 2, 3 , 4]. Steels thixoforging is in industrial developing. The difficulties are related to specific technical constraints and the understanding of the complex flows of semi-solid material and the tool / material interactions during forming [4].

Instrumented extrusion experiments used to determine the key parameters influencing the thixoforging $[5,6]$ (the speed of the tool, the temperature of the billet and the tool temperature) helped to highlight the great influence of heat exchange between tool and workpiece on the result even if the forming time is extremely short (less than $0.5 \mathrm{~s}$ ). Compared to other models for metal alloys at semi-solid state [7], a multi-scale "micro-macro" model considering the two-phase nature of the semi-solid and taking into account the microstructures evolution, the behavior of both phases and has been developed and implemented in Forge ${ }^{\circledR}$ to simulate the steel thixoforging at semi-solid state [8-10].

The comparison between the experimental and the simulated results can provide informations to understand the occurrence of certain phenomena during the extrusion, to assess the predictive model and to identify the parameters of the model. 


\section{DATA AND PARAMETERS OF SIMULATION FROM A REAL THIXOEXTRUSION EXPERIENCE}

The presented simulations and experiments correspond to the thixoextrusion of C38 steel at semisolid state with less than 20 percent of liquid-fraction.

\section{Thixoextrusion experiments}

The extrusion tests consist in deforming a $30 \mathrm{~mm}$ diameter steel slug at semi-solid state to $40 \mathrm{~mm}$ diameter and reducing it immediately by filling to diameter of $12 \mathrm{~mm}$. The C38 steel slug, of $30 \mathrm{~mm}$ diameter and $45 \mathrm{~mm}$ height, is heated uniformly at a temperature of $1420{ }^{\circ} \mathrm{C}$ with an inductive furnace [5-6.10]. The filing tool at room temperature $\left(30^{\circ} \mathrm{C}\right)$ moves at a constant speed of $50 \mathrm{~mm} / \mathrm{s}$ during the entire forming with a specific device mounted on a high speed hydraulic press [5$6,10,11]$ (extrusion test "50CL85").

\section{Thixoforging simulations}

The simulations with Forge ${ }^{\circledR}$ software are similar in terms of forming conditions to the experimental tests described above. The adjustable simulation datas are modified (solid bonds consistency, exchange coefficient between slug and die, etc.) and the numerical evolution of forging force and the temperatures in the tool during extrusion are compared with experimental results.

Process modeling The modeled geometry is limited to an axial half-section (figure 1a). The numerical shape of the filing cylinder diameter of $12 \mathrm{~mm}$ was changed and made with a conical slope of $0.4^{\circ}$. Without this shape there is numerically no contact between the $12 \mathrm{~mm}$ diameter filled material and the tool. During the simulate forming, without this artificial contact, there is no significant temperature increase in the tool while there are one in the reality. The mesh size is approximately $1 \mathrm{~mm}$ and adjustable during the simulation.
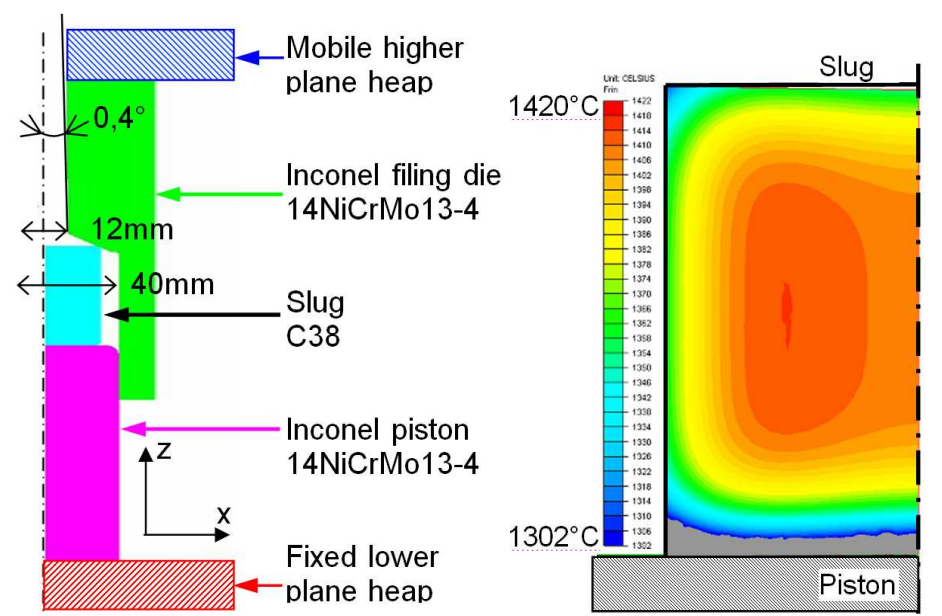

Fig.1. a) numerical modelling from extrusion tools. b) simulated temperatures of the billet before forming.

Different simulation parameters The friction of semi-solid steel on the filing tool is modelled by a Tresca limited Coulomb law, the friction parameters are adjustable.

The thermal modelling is based on the heat equation and the thermal boundary conditions involving the heat losses, the thermal conduction within the semi-solid slug and the die. The latent heat associated to the liquid-solid phase transformation is not considered here. Heat exchange between the semi-solid steel and the tool are mainly due to conduction. The heat transfer coefficient $\mathrm{H}(10000 \mathrm{~W} / \mathrm{m} 2 . \mathrm{K})$ is determined by inverse method with an instrumented compression test [10]. The simulations do not take into account the internal plastic dissipation. The simulated temperatures in the billet before forming corresponds to that obtained in the case of induction heating (figure 1b).

The initial solid fraction for calculation is setup and adjusted to 0.8 using Sheil model as function of the material, the temperature and its evolution. 
Behavior law The tests are simulated first using a Norton-Hoff behaviour law in order to obtain orders of magnitude of some parameters. Norton Hoff law has common evolution parameters with the micro-macro law developed to represent the behaviour of an alloy at the semi-solid state [8-9]. The behaviour law of solid globules and that of solid bonds of active fraction used in the micromacro law is similar to the Norton-Hoff law. The noticeable difference lies in the fact that the liquid fraction evolves during the forming process. The Norton-Hoff behaviour law involves the strain rate and a consistency $\mathrm{K}$ evolving exponentially according to the temperature of the semi-solid material.

$$
s=2 * K(T, \bar{\varepsilon})(\sqrt{3} \dot{\bar{\varepsilon}})^{m-1} \dot{\mathcal{\varepsilon}} \quad \text { (1) and } K(T, \bar{\varepsilon})=K_{0} *\left(\bar{\varepsilon}+\bar{\varepsilon}_{0}\right)^{n} * e^{\frac{\beta}{T}}
$$

- K0, initial consistency,

- n, strain hardening sensitivity parameter,

- $\quad \beta$, term of temperature,

- $\mathrm{m}$, strain rate sensitivity parameter.

Table 1: Values of parameters used for the Norton-Hoff and the multi-scale behaviour laws.

\begin{tabular}{|c|c|c|c|}
\hline \multicolumn{3}{|c|}{ Solid consistency } & strain rate sensitivity parameter \\
\hline $\mathrm{K}_{0}$ & $\mathrm{n}$ & Beta & $\mathrm{m}$ \\
\hline 9 MPa.s & 0,08 & 700 & 0,3 \\
\hline
\end{tabular}

The different coefficients of the Norton-Hoff law are selected at first instance using simulations of compression and direct extrusions carried out by P. Cézard and E. Becker [10]. The behaviour of the steel is also modelled by the multi-scale model "micro-macro" for a Representative Elementary Volume (VER) [8-9].

$$
\underline{\underline{S}}=2 \mu_{S S} \underline{\underline{\varepsilon}}
$$

$-\quad \underline{S}=$ deviatoric part of the stress tensor,

- $\quad \underline{\underline{\dot{\varepsilon}}}=$ strain rate tensor,

- $\mu_{S S}=$ effective viscosity.

The effective viscosity of the VER is shown after a first scale transition as follows:

$$
\mu_{S S}=f_{A} \cdot \mu_{A} \cdot T_{A}+f_{I} \cdot \mu_{I} \cdot T_{I}
$$

$-f_{A}=$ fraction of active zone,

$-\mu_{A}=$ viscosity (active zone),

$-T_{A}=$ tensor of localization,

- $f_{I}=$ fraction of inactive zone.

The evolution of the active solid fraction is modelled as follows:

$$
\dot{f}_{A}^{s}=K_{a g} \cdot(-\dot{T})^{b} \cdot f^{s} \cdot\left(1-f_{A}^{s}\right)-K_{d g} \cdot\left(1-f^{s}\right) \cdot f_{A}^{s}\left(\sqrt{3} \cdot \dot{\varepsilon}_{A}^{s}\right)_{e q}^{n}
$$

- $K_{a g}=$ term of agglomeration

$-K_{d g}=$ term of disagglomeration

- $\quad \dot{T}=$ temperature variation and $b$ et $n=$ material parameters

Table 2: Values of parameters used for the behaviours law of multi-scale "micro-macro"

\begin{tabular}{|c|c|c|c|c|c|c|c|}
\hline \multicolumn{8}{|c|}{ Parameters associated with the bonds behaviour (active zone) } \\
\hline Morphological motif & Agglomeration & Disagglomeration & \multicolumn{4}{|c|}{ local Laws } \\
\hline $\mathrm{f}_{\mathrm{A}}$ & $\mathrm{f}_{\mathrm{A} \text { initial }}^{\mathrm{s}}$ & $\mathrm{K}_{\mathrm{T}}$ & $\mathrm{b}$ & $\mathrm{K}_{\mathrm{d}}$ & $\mathrm{K}_{\mathrm{p}}$ & $\mathrm{m}_{\mathrm{p}}$ & $\mathrm{K}_{1}$ \\
\hline 0,025 & 0,4 & 1 & 1 & 0,1 & $\mathbf{1}$ MPa.s & 0,17 & $1,81.10^{-9}$ MPa.s \\
\hline
\end{tabular}

The parameters of the micro-macro law for C38 steel at the initial temperature of $1420^{\circ} \mathrm{C}$ were determined and optimized by successive simulations (Table 2). 
Simulated displacement from tool The movement of the tool was implemented in Forge ${ }^{\circledR}$ according to the measured displacement curve obtained experimentally during forming (figure 2).

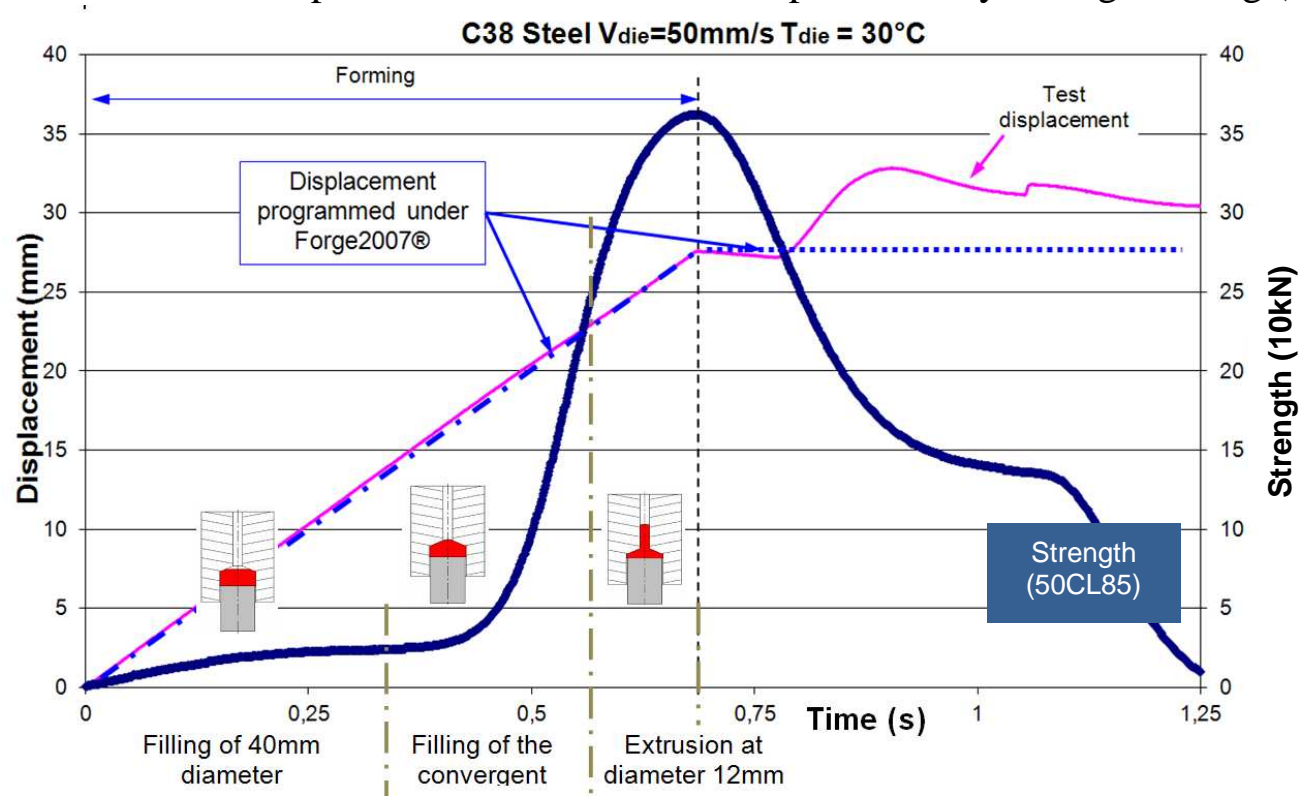

Fig.2. Simulated and experimental (50CL85) displacement of forming tool versus time and strength versus time [10]

\section{SIMULATIONS RESULTS}

In this paper, the results are presented and compared to the experimental extrusion test, the evolution of forming load versus displacement of the tool and the maps of the solid fraction and the flow rate of the material.

\section{Simulated results with the Norton-Hoff behaviour law}

Figure 3 shows two displacements - forming load curves simulated with the Norton-Hoff behaviour law for extrusion with a die having a cylindrical filing part and another die having a conical filing part with a slope of $0.4^{\circ}$. Phases of filling of the cylinder of diameter of $40 \mathrm{~mm}$ and of convergent are the same for both simulations and confirm that the difference in geometry of the cylinder diameter of $12 \mathrm{~mm}$ doesn't influence these stages of the forming process. In the simulations, the filling stage starts later and takes less time and ends later than for experimental testing. The later filling of the convergent is explained by a difference in volume of the billet between the nominal size used for simulations and the true volume of the billet undergoing the thermal expansion of the material. The shorter filling time of the convergent can be explained by the fact that the clearance between the punch and the die generates backward extrusion this phenomenon not being taken into account in the simulation. The slope of the simulated forming load curve in the filing phase of the convergent is larger than that of the experimental test and the maximum value of the forming load at the end of this stage is greater. These differences between simulation and experiment can be explained by the choice of simulations parameters like a too great consistency, a too high strain hardening exponent, a too high strain rate sensitivity or a too high heat exchange coefficient between the formed material and the tool. 


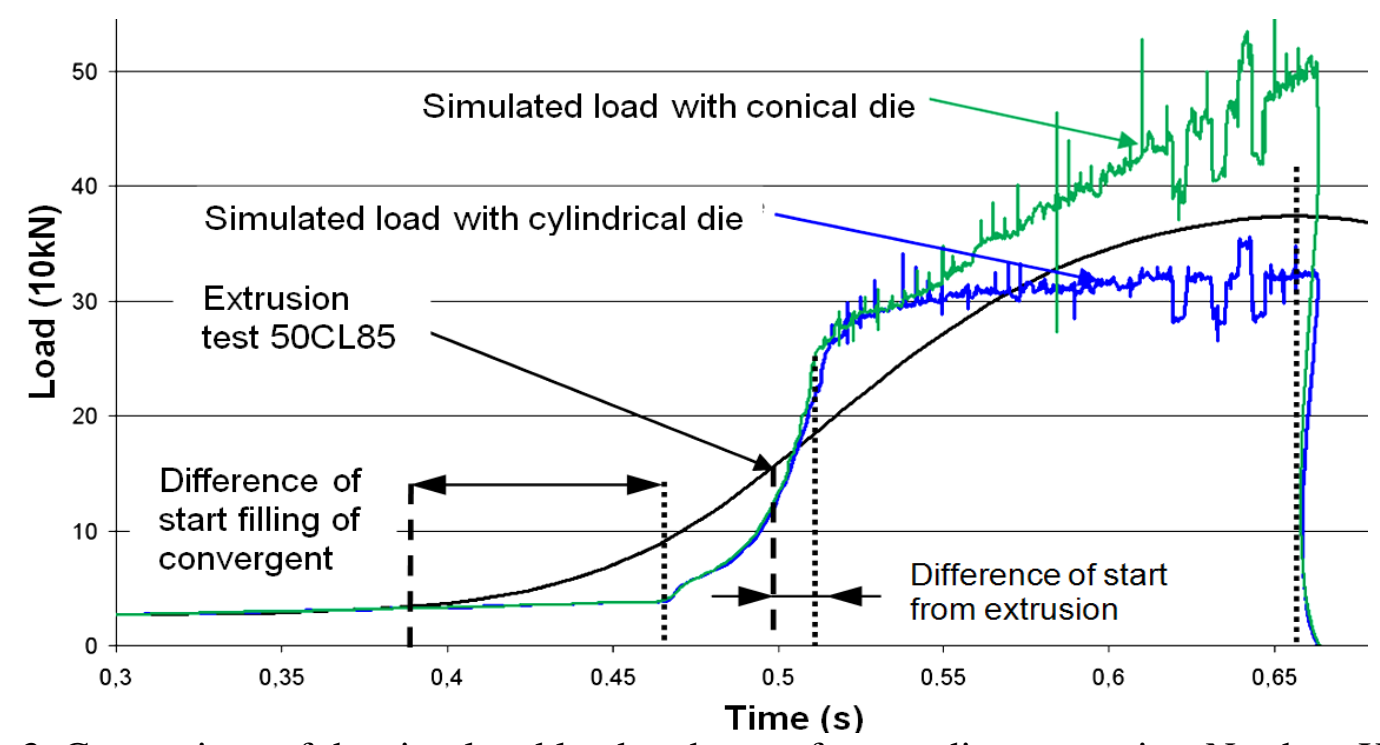

Fig.3. Comparison of the simulated load at the test for two die geometries; Northon-Hoff parameters: $\mathrm{K} 0=9, \mathrm{n}=0,08, \mathrm{~b}=700, \mathrm{~m}=0,3, \mathrm{mu}=0,15$ and $\mathrm{H}=10000$

In the case of the cylindrical die, the forming load is not correct during the filling stage of the die diameter of $12 \mathrm{~mm}$, the effects of friction of the material on the tool is not taken into account. In the case of the conical die, the friction as well as the necessary deformation for the material to enter the die, generates an increase in forming load. The evolution of simulated load in this last stage is more linear than that observed experimentally. Figure 4 shows the influence of the initial consistency K0 and the strain hardening sensitivity $\mathrm{n}$ on the displacement forming load curve.

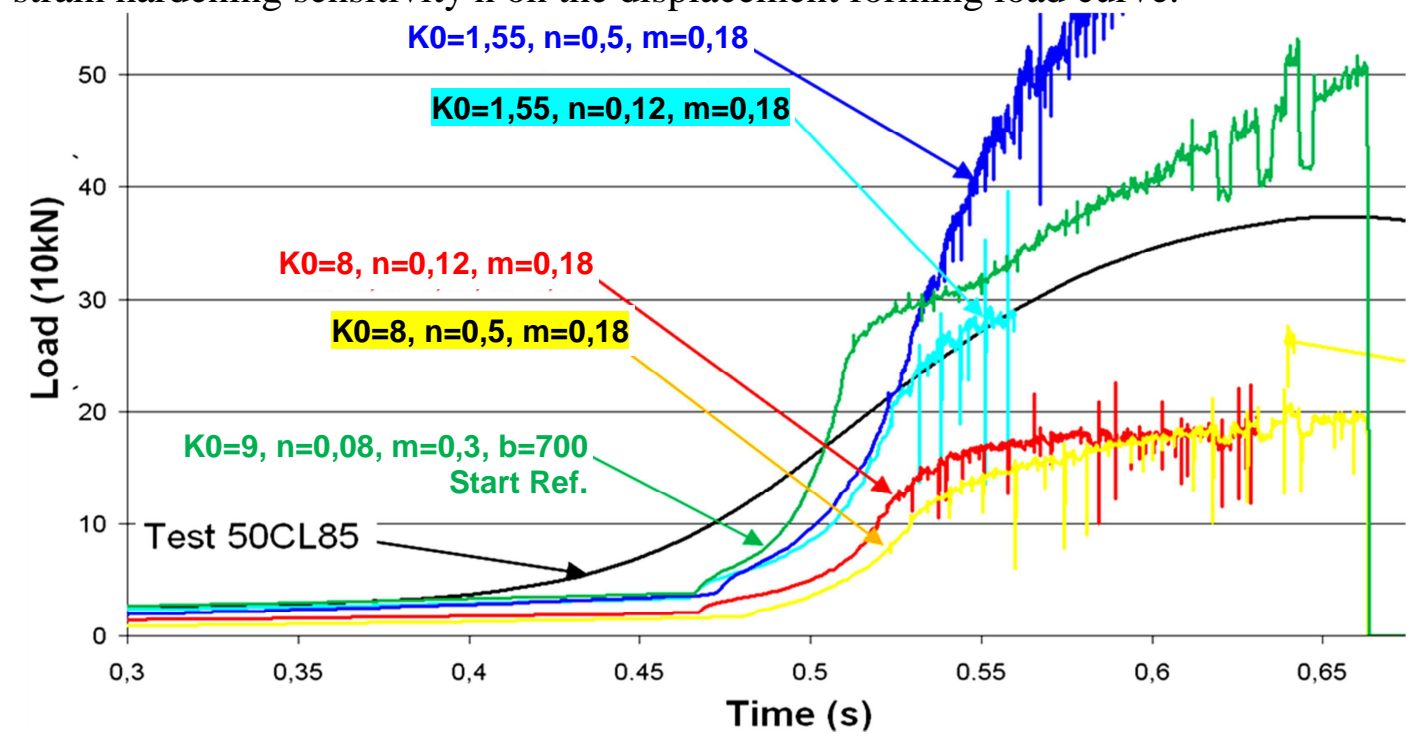

Fig.4. Influence of different parameters of the behaviour law Norton-Hoff on the forming load evolution simulated.

The consistency K0 influences the slopes of the load curve above all that corresponding to the filling of the convergent. The parameter $\mathrm{n}$ acts on the slope and the curvature of the die filling stage, smaller it is and smaller the slope and curvature of the curve are. After several simulations, the favourable case corresponds to a consistency K0 close to $2 \mathrm{MPa}$.s and a parameter n close to 0,12 . 


\section{Simulated results with the multi-scale model "micro-macro"}

The evolution of the simulated load with the micro-macro law is almost identical to that obtained with the Norton-Hoff law as shown in, figure 5. For the same reasons the thixoforging load simulated (Figure 4) with the micro-macro model does not give a satisfactory result for the stages corresponding to the filling of convergent and the extrusion. The filling phase of the convergent starts later and the slope of the extrusion phase is slightly higher.

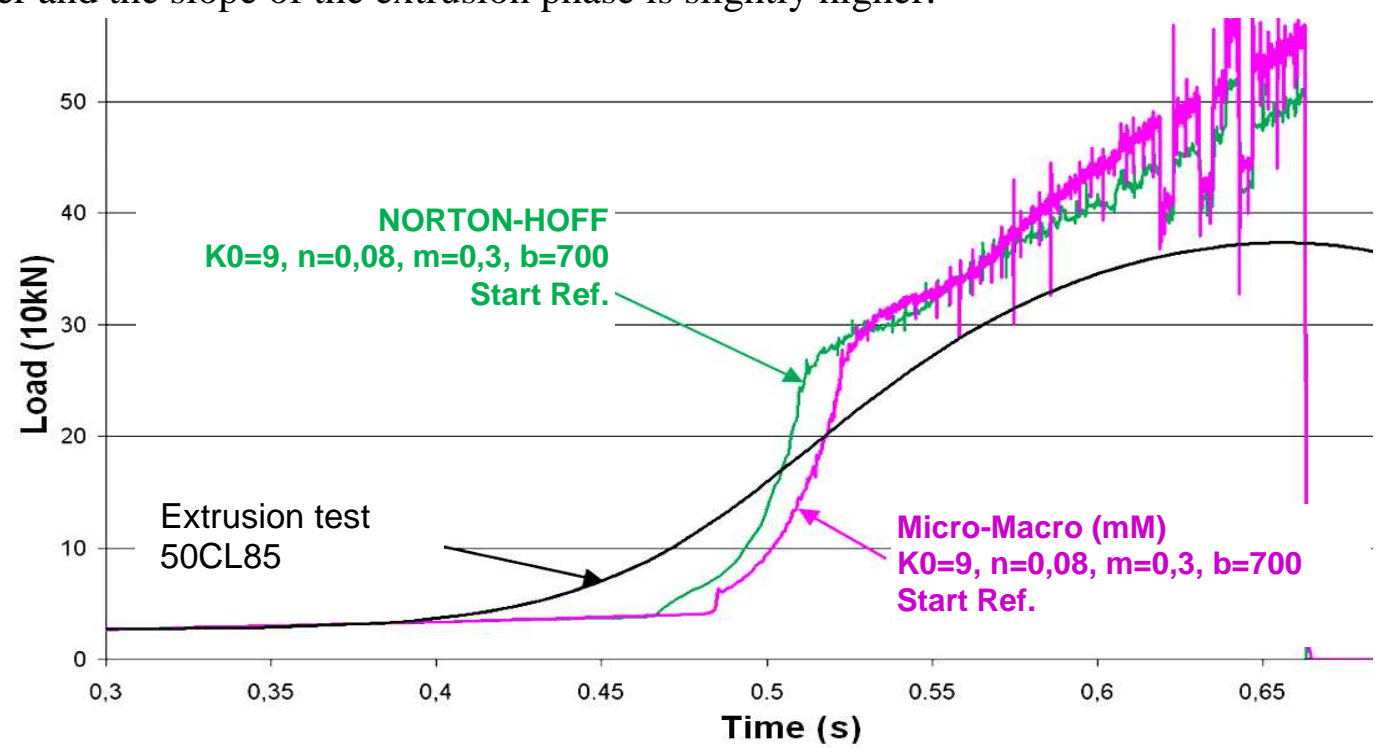

Fig.5. Comparison of the evolution of the simulated load with the Norton-Hoff law and micromacro law for an extrusion test (conical die).

To improve the predictive aspect of the simulations, it is necessary to adapt the model parameters. In the previous paragraph, the simulated forming load with the micro-macro behaviour law increases too fast in the extrusion phase. As simulations with Norton-Hoff have shown that the consistency changes the slope of the strength curve, the effect of the consistency was also studied with the micro-macro model. In figure 6, the strength curves are obtained for different solid bond consistencies. When the solid bond consistency Kp decreases, logically, the slopes of the forming load curve decreases and particularly during the extrusion stage.

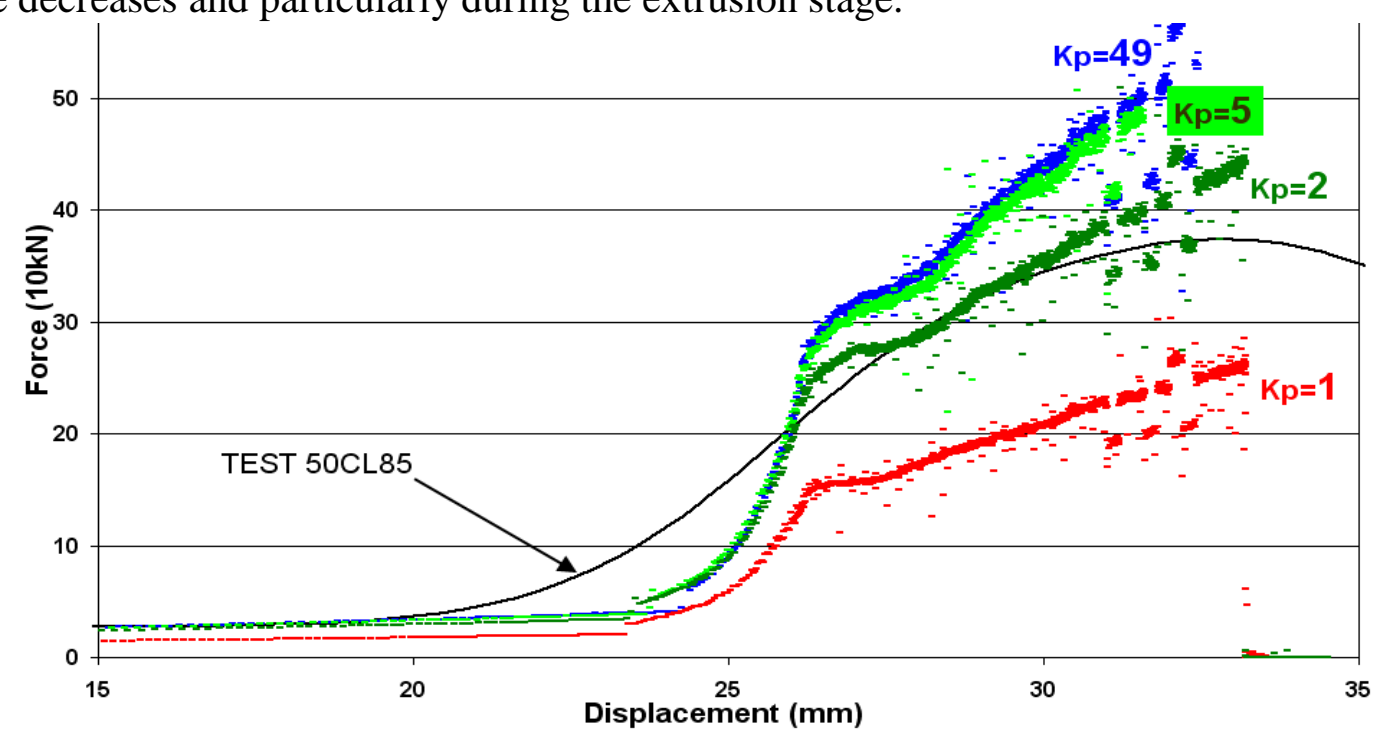

Fig.6. Evolution of the simulated thixoforging load with the micro-macro law for different consistencies of solid bonds.

It is for a solid bond consistency $\mathrm{Kp}$ of 2 that the simulated strength curve is the closer to the experience. This consistency corresponds to the bond between the solid particles. These bonds are the weakest parts in the solid phase, modelled for the simulation as a continuous skeleton. This 
value of 2 is less than the consistency of the solid phase K0 equal to 9, which corresponds to the physical reality.

Table 3 shows the evolution of the solid fraction, the consistency and the material flow for the simulated thixoforging using Forge ${ }^{\circledR}$ and multi-scale model "micro-macro". The line "a" of table 3 presents the evolution of the solid fraction during thixoforging. Three specific flow areas for this kind of metal forming are noticeable on the experimental test and simulation. The first zone $\mathrm{F}$ corresponds to a conventional hot forging flow, the associated fiber structure is typical. The second zone with low plastic flow (zone D) is mainly localized in the convergent where heat exchange is very high and its fiber structure is similar to that of the $\mathrm{F}$ area. The material in the $\mathrm{E}$ zone of the specimen has undergone smaller heat exchange and remains semi-solid during forming. These three specific flow zones are also visible on the evolution of the simulated solid fraction, their geometries are only slightly different. The area D should be less important in the diameter of $12 \mathrm{~mm}$ from die and distinct as area F. The row "b" of Table 3 shows different flow velocities of the material in the die diameter of $12 \mathrm{~mm}$, whereas in the ideal case they must be identical and constant. This observation helps to explain in some extreme thixoforging occurrence of shape defects.

Table 3: Evolution of the solid fraction and the flow velocity of material for direct extrusion simulated with Forge ${ }^{\circledR}$ and multi-scale model [10].

a)

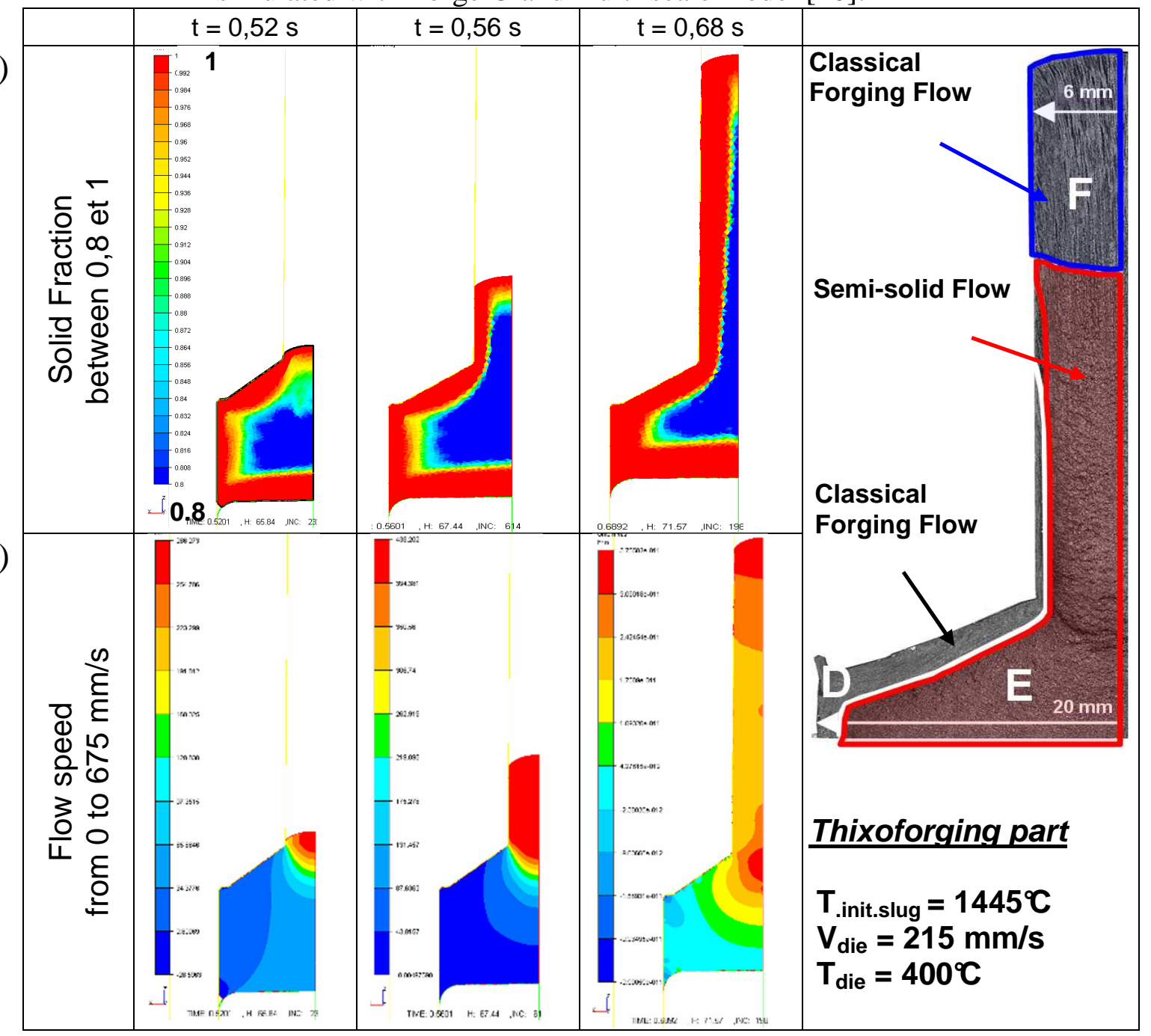

\section{CONCLUSION}

The first numerical simulations of extrusion test with the Norton-Hoff behaviour law helped to identify the importance of friction, heat exchange and the influence of some parameters of the constitutive law on the results. The implementation of the multi-scale behaviour law "micro-macro" 
confirms the values of the model of Norton-Hoff. These numerical works and the experiences highlight the impact of heat on the material flow and consequently on the part structures. The sensitivity study shows the importance of all parameters and their dependence. Operated for the case of a complex tooling design, as piston shown in Table 4, the micro-macro model helped to identify the areas with the highest liquid fraction during the forming and their evolution. This application also highlights the difficulty to identify the thermal parameters on complex geometries as for conventional forging.

Table 4: Simulated validation of tool of the piston ENSAM Metz by using Forge ${ }^{\circledR}$ and the multi-scale model "micro-macro" [10].

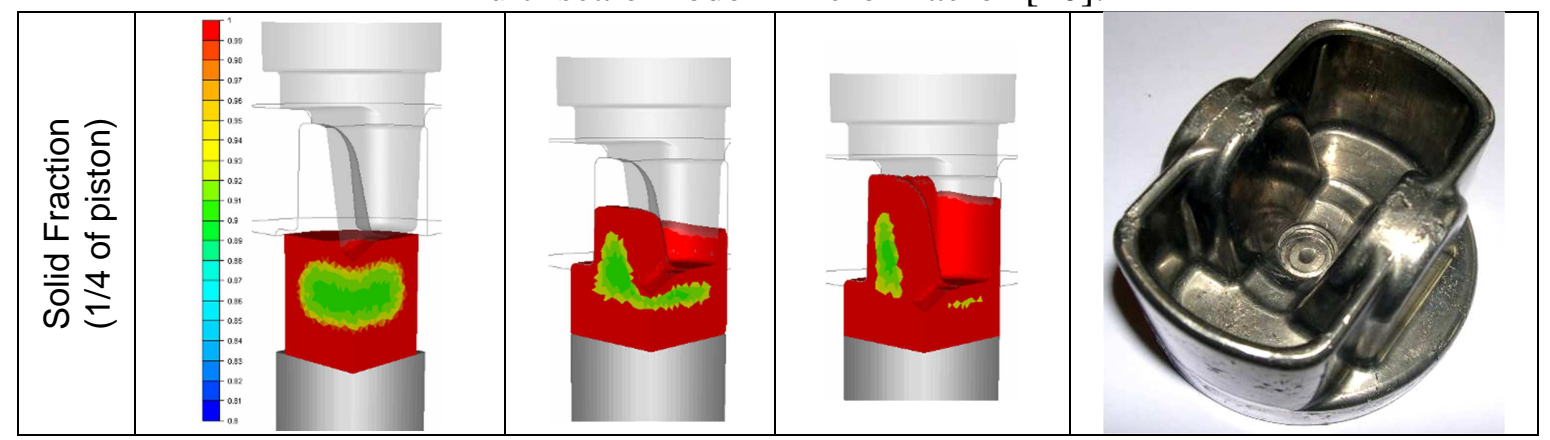

\section{Acknowledgement}

Authors would like to thank, Thomas GELMETTI and Philippe PIGNAL, for their support.

\section{References}

[1] Cezard, P. and al., Thixoforming of Steel : a state of the art from an industrial point of view. Journal Solid State Phenomena, 2008. 141-143.

[2] Puttgen, W., and al., Thixoforming of steels - A status report. Advanced Engineering Materials, 2007. 9(4): p. 231-245.

[3] Hirt, G. and al., Thixoforming. Book, Wiley éd., 2009, ISBN: 978-3-527-32204-6.

[4] Bigot, R. and al., Some approaches on industrialization of steel thixoforging processes. Solid State Phenomena, Volume 192-193, 2013, Pages 521-526.

[5] Becker, E., and al., Metallurgical and mechanical analysis from thixoforging steel shape. International Journal of Material Forming, Volume 1, Issue SUPPL. 1, July 2008, Pages 977-980.

[6] Cezard, P., et al. Thixoforming of Steel: New Tools Conception to Analyse Thermal Exchanges and Strain Rate Effects. AIP Conference Proceedings, 10TH ESAFORM conference, Volume 907, 2007, Pages 1155-1160.

[7] Modigell, and al., Two-phase simulations as a development tool for thixoforming processes. Steel Research International, Volume 75, Issue 8-9, August 2004, Pages 513-518.

[8] Favier, V., et al., Transient and non-isothermal semi-solid behaviour: 3D micromechanical modelling. Materials Science and Engineering A, Volume 517, Issue 1-2, 20, 2009, Pages 8-16.

[9] Favier, V., et al., Modelling of Semi-solid Processing, Chapter 6: Micromechanics and Homogenization techniques for Disordered Materials: Applications to semi-solid materials. Helen V. Atkinson ed. 2008.

[10] Becker, E., Investigations expérimentales et numériques pour l'identification des paramètres clefs du procédé de thixoforgeage de l'acier sur le produit mis en forme, thesis, 2009.

[11] Becker, E., Steel thixoforging: heat exchange impact on the mechanical and metallurgical features of thixoforged samples, Solid State Phenomena Vols. 141-143, 2008, Pages 701-706. 